\title{
EL VISITADOR GENERAL DEL VIRREINATO DEL RÍO DE LA PLATA, DIEGO DE LA VEGA, Y LAS IRREGULARIDADES EN LAS CAJAS REALES ALTOPERUANAS (1802)
}

\section{THE INSPECTOR GENERAL OF THE VICEROYALTY OF RIO DE LA PLATA, DIEGO DE LA VEGA, AND IRREGULARITIES IN THE UPPER PERUVIAN ROYAL CASH BOXES (1802)}

\author{
María Concepción Gavira Márquez \\ Universidad Michoacana de San Nicolás de Hidalgo, Morelia, México, \\ cgaviram@hotmail.com
}

Resumen. La presente investigación aborda el descontrol administrativo de la Real Hacienda y el grado de responsabilidad de la burocracia en la crisis fiscal en el virreinato del Río de la Plata a partir del análisis de una importante visita producida a principios del siglo XIX, periodo del supuesto avance de las reformas borbónicas. A través del estudio de las irregularidades y quiebras de las Cajas Reales altoperuanas, se cuestiona la eficacia de dichas reformas en la administración de los recursos, además de analizar el papel de los oficiales reales e instituciones fiscalizadoras.

Palabras clave: fiscalidad colonial; reformas borbónicas; virreinato del Río de la Plata.

Abstract. This research addressed the administrative decontrol of the Royal Treasury and its level of responsibility in the tax crisis in the Viceroyalty of Rio de la Plata based on the analysis of an important visit that took place at the beginning of the XIX century, alleged period of progress in the Bourbon reforms. Through the study of the irregularities and collapse of the Royal Cash Boxes of upper Peru, it questions the efficiency of the aforementioned reforms in the administration of resources, in addition to analyzing the role of the royal officials and taxation institutions.

Key words: colonial taxation; Bourbon reforms; Rio de la Plata viceroyalty.

Fecha de recepción: 10 de septiembre de 2014. Fecha de aceptación: 7 de mayo de 2015.

Am. Lat. Hist. Econ., año 23, núm. 1, enero-abril, 2016, pp. 90-118 
Cuando el hombre se apasiona por el interés o el capricho, ni la ley le detiene ni la razón le hace fuerza, los conceptos los trunca, lo pequeño le parece grande y a todo se avanza sin prever el riesgo...

Diego de la Vega. ${ }^{1}$

\section{INTRODUCCIÓN}

$\mathrm{E}$ 1 primer régimen de intendencia que se estableció en el continente americano fue en el virreinato del Río de la Plata en 1782 (San Martino, 1999). La premura en este virreinato fue producto de la situación de crisis y conflicto que la sublevación indígena había conseguido establecer en gran parte de su jurisdicción, especialmente en el Alto Perú. Este levantamiento indígena que se dio de manera simultánea en distintos lugares se extendió por el altiplano andino y alcanzó un importante impacto en gran parte del virreinato. Una de las quejas de los indígenas sublevados fue la extorsión y los abusos de los corregidores. La reforma administrativa a partir de la aplicación del régimen de intendencias contemplaba, entre otros objetivos, acabar con la odiosa figura del corregidor de indios y sustituirla por los subdelegados.

La Real Ordenanza para el establecimiento e instrucción de intendentes de ejército y provincia en el virreinato de Buenos Aires en 1782, conocida como la Real Ordenanza de Intendentes, fue aplicada en los territorios americanos durante el reinado de Carlos III. Según estudiosos como Mariluz (1995, p. 84), esta legislación es fiel reflejo del pensamiento ilustrado, pues muestra las respectivas funciones de la metrópoli y las colonias. En todo caso, el objetivo era potenciar al Estado aumentando a la vez sus recursos, para ello había que consolidar un buen cuerpo de funcionarios capaces de gestionar y aumentar los capitales y bienes de la Real Hacienda. La visita del contador Diego de la Vega al virreinato del Río de la Plata puso en evidencia este nuevo cuerpo de funcionarios, especialmente a los intendentes como responsables inmediatos de la administración de los recursos de la Real Hacienda en las diferentes provincias.

El análisis de esta visita de Diego de la Vega al virreinato del Río de la Plata en 1802 nos ayudará a estimar la eficacia de las reformas fiscales y la situación del virreinato en la administración de la Real Hacienda, además de evaluar los resultados de la aplicación del sistema de intendencias como programa cumbre de las reformas borbónicas en cuanto a la reforma fiscal

${ }^{1}$ Diego de la Vega a Cayetano Soler. Buenos Aires, 24 de diciembre de 1803, Buenos Aires, 370, núm. 80. Archivo General de Indias (en adelante AGI). 
y aumento de los recursos para la corona. Tres escandalosas "quiebras" se analizarán en este avance de investigación para abordar las actividades de la burocracia fiscal, sus relaciones con las elites locales y, finalmente, su responsabilidad en las irregularidades cometidas con los capitales de las Cajas Reales. Utilizaremos el término quiebra porque es el que aparece en la documentación y lo entendemos tal y como lo plantea José Canga Argüelles (1827) en su Diccionario de Hacienda:

Esta vos en Hacienda, lo mismo que en el comercio, representa el estado de falencia de los que manejan los fondos públicos; es decir, cuando de la liquidación de sus cuentas aparece que han recibido mayores sumas que las de que dan legítima salida en ellas. La quiebra puede provenir, o de haber invertido en sus propios usos los caudales de la hacienda el que los tenía a su disposición, o de haber usado de ellos con ánimo de reintegrarlos. En uno y otro caso, aunque los reintegre, todo depositario, tesorero o administrador queda privado de empleo, e inhabilitado de poder obtener otro alguno en el servicio de S. M. (p. 532).

Por lo tanto, se cuestiona principalmente el concepto de eficacia de las reformas borbónicas en el plano de la fiscalidad en el virreinato del Río de la Plata. ${ }^{2}$ La llamada "revolución en el gobierno" de Brading (1975) para nombrar el proceso de reformas implementadas a la llegada de José de Gálvez al gobierno de las Indias, nos parece muy lejos de la situación en la que se encontraba la administración colonial del nuevo virreinato del Río de la Plata. Algunos estudiosos como Garavaglia (2012) para este virreinato, y Salvucci (1983) para el de Nueva España, no perciben cambios en las prácticas sobre la burocracia durante las últimas décadas del siglo XVIII. En nuestros trabajos (Gavira, 2005 y 2008) sobre las Cajas Reales de algunos de los centros mineros altoandinos tampoco encontramos ninguna "revolución" o cambio en el ejercicio y manejos de la administración local. Se debe entonces reconocer que la falta de éxito del proyecto borbónico se encontraba estrechamente relacionada con el ejercicio y estrategias de una burocracia inserta dentro de las elites locales, cuestión que deberemos abordar en una etapa posterior de esta investigación, teniendo en cuenta la tesis que plantea que esta flexibilidad era la que permitía que se

${ }^{2}$ Según Pérez Herrero, las interpretaciones sobre la eficacia de las reformas borbónicas provienen de la historiografía dieciochesca ilustrada europea liberal y decimonónica latinoamericana. Un ejemplo significativo fue el mismo Humboldt. En las décadas de los setenta y ochenta del siglo pasado, importantes estudiosos asociaron los resultados fiscales con el éxito de las reformas borbónicas (Brading, 1975; Fisher, 2000; Lynch, 1989). En el caso que se analiza en este trabajo, ni siquiera encontramos este supuesto para mantener la tesis de éxito de las reformas en la cuestión fiscal. Una revisión de la historiografía sobre el tema de las reformas borbónicas se encuentra en Pérez (1991) y en Salvucci (1983). 
mantuvieran las relaciones entre las colonias y la metrópoli. ${ }^{3}$ Garavaglia (2012) cuestiona igualmente esta "racionalización" supuesta a la burocracia durante el periodo cercano a la revolución de independencia y señala los múltiples casos de una burocracia fiscal vinculada a las elites locales (generalmente a través del matrimonio), cuando a pesar de la legislación los cargos hacendísticos se compraban y se heredaban (pp. 10-14). También Moutoukias (1988), en su análisis sobre el contrabando y la "corrupción” de los cargos locales en el Buenos Aires del siglo XVII, plantea la existencia de una red de notables compuesta por una mezcla de la elite económica y la burocracia, donde los representantes de la corona tenían un espacio importante y donde las prácticas económicas, incluidas las transgresiones, fortalecían al conjunto: a la corona, a sus representantes y a las mismas elites. Sin embargo, en el siglo XVIII, debemos pensar que la coyuntura cambió y que la corona rompió o intentó romper ese pacto de reciprocidad, sin obtener grandes resultados según las evidencias que nos presenta la visita de Diego de la Vega. A pesar del crecimiento del siglo XVIII, e incluso del aumento de la fiscalidad, los recursos no llegaban hasta la península y a veces ni siquiera a Buenos Aires, en los casos que analizamos en este trabajo los excedentes de las Cajas provinciales se quedaban en el ámbito local, financiando los negocios de las elites locales entre las cuales se encontraba inserta la burocracia.

La visión de la historiografía es unánime al considerar la corrupción en las colonias durante el siglo XVII como generalizada y de carácter sistemático (Andujar y Felices de la Fuente, 2011; Jiménez, 2012; para el caso concreto de las colonias americanas véase Michel Bertrand, 1989 y 1999; Pietschmann, 1987); ${ }^{4}$ sin embargo, para el siglo XVIII se mantiene una visión más polémica en torno a los resultados de la nueva burocracia borbónica. Uno de los objetivos más perseguidos por estas reformas fue la implantación de una burocracia eficaz y leal, con capacidad de servicio público y respeto por la ley. Para ello se concibió un proyecto de reforma administrativa que se basaba en cuatro principios fundamentales: el primero consistía en poner la administración pública bajo el Estado, es decir, rescatar todos los oficios enajenados por particulares; el segundo consistiría en que todas las funciones de la administración pública queda-

\footnotetext{
${ }^{3}$ Pietschmann (1987) propone que el Estado colonial aun en plena época de reformismo borbónico omitió conscientemente la aplicación general de las normas. En el caso más concreto de los oficiales reales que nos ocupan, Michel Bertrand (1999) apunta a la dificultad que suponía la distancia geográfica entre la metrópoli y las colonias a la hora de exigir el estricto cumplimiento, por lo tanto se podían permitir una importante autonomía en el ejercicio de estos oficios, alentada por la poca rigidez y eficacia de los castigos.

${ }^{4}$ Bertrand destaca los estudios sobre la administración más actuales, los cuales recurren el método prosopográfico.
} 
sen a cargo de verdaderos profesionales nombrados por su preparación y competencia; el tercero suponía realizar una completa modernización de las técnicas administrativas, y el cuarto residía en la observancia de la ley (Céspedes, 1983, pp. 224-264). El cumplimiento de estos objetivos es lo cuestionable.

Los estudios sobre la historia fiscal, especialmente los basados en la contabilidad de la Real Hacienda durante el siglo XVIII de los distintos virreinatos, fueron considerables en las últimas décadas del siglo XX y principios del XXI, pero siempre fueron más abundantes los que abordan el virreinato de Nueva España que los de otros territorios coloniales. ${ }^{5}$ Para el virreinato de Nueva España, la historiografía ha presentado de forma general un crecimiento importante en el siglo XVIII que se tradujo en un importante aumento de su aportación a las arcas reales a partir de una fiscalidad mucho más eficaz que recaía en todos los rubros económicos en crecimiento y en el aumento demográfico. Las cuentas de la Real Hacienda evidenciaron un mayor crecimiento a partir de la década de 1780, cuando se concentraron las medidas reformistas de los Borbones. El aumento de la fiscalidad ha sido abordado al evidenciar los distintos desarrollos regionales, como lo hizo Klein (1985) y Klein y Santos (1973) para los distintos virreinatos. En el caso del virreinato del Río de la Plata, de reciente creación en 1776, no es posible abordar todo el siglo XVIII de forma homogénea, pero todo indica que el crecimiento de la fiscalidad no fue constante ni propició el aumento de los recursos de la Real Hacienda. ${ }^{6}$ Klein (1985) ha presentado un estudio detallado de los ingresos y los gastos del virreinato del Río de la Plata en 1790 y ha llegado a la conclusión que el disminuido excedente que producía este virreinato escasamente servía para mantenerse a sí mismo. En 1790 se transfirió la corona a poco más de 100000 pesos y entre 1790 y 1795 hubo años en que no se remitió ningún dinero a la península (Klein y Santos, 1973, p. 395).

En este trabajo no tenemos la intención de hacer una evaluación de los impuestos ni los excedentes, se trata de presentar y analizar las quiebras

${ }^{5}$ Para el caso mexicano, Luis Jáuregui (2003, pp. 725-771) presenta una interesante revisión de la literatura sobre la historia fiscal. Sobre el virreinato del Río de la Plata fundado a partir de 1776 hay menos trabajos en su consideración de jurisdicción territorial. Algunos de los autores que abordaron la historia económica y fiscal colonial del virreinato del Río de la Plata son: Klein (1973 y 1985), Garavaglia (2012), Saguier (1992), Halperin Donghi (1982), Santamaria, Gelman, Marquiegui, Millones y Garavaglia (1990), Moutoukias (1988 y 2010) y Moutoukias y Amaral (2010).

${ }^{6}$ Con la creación del virreinato del Río de la Plata, y aún antes, se implementaron en el Alto Perú una importante reorganización fiscal destinada a subsidiar este nuevo virreinato. Estas medidas entre las que se encontraba la creación de nuevas cajas reales, y especialmente el envío de diferentes remesas a Buenos Aires significaron un gran apoyo a las elites y la consolidación de los circuitos comerciales que se generaban o destinaban en esta ciudad (Santamaria, Gelman, Marquiegui, Millones y Garavaglia, 1990). 
de algunas de las Cajas Reales altoperuanas, las cuales eran el sustento económico del virreinato. Como sabemos, la Caja Real de Potosí a través del situado financiaba el nuevo virreinato, sin embargo, aunque se alude a la crisis de la minería, Potosí tuvo un repunte a partir de 1780 hasta 1800 (Tandeter, 1992, p. 14). La disminución de las transferencias de estos recursos a la Caja Real de Buenos Aires, como dependencia principal de la Real Hacienda, es clave para entender esta escasez de excedentes y quizá no debamos reducir la disminución a la tan aludida crisis minera. ${ }^{7}$ El siglo XVIII no fue un siglo de crisis, a pesar de algunas coyunturas adversas manifestó un crecimiento sostenido en la población y en algunos centros en la producción minera (Tandeter, 1995). Nuestra propuesta efectivamente no es que los impuestos no aumentaran, como podremos evidenciar en algunas de estas Cajas Reales, la cuestión es plantear por qué no funcionó el proceso de transferencia de los excedentes que se debían destinar vía Buenos Aires hacia la península. ${ }^{8}$ Quizá la explicación de esta falta de éxito de la reforma fiscal borbónica radique en cuestiones internas que nos expliquen el motivo por el cual no se recaudaron los impuestos (caso de la Caja Real de La Paz) o conocer dónde se destinaron estos recursos. Estas dos últimas cuestiones serán abordadas en este trabajo a partir de tres casos concretos de Cajas Reales: Oruro, Carangas y La Paz.

Según señala Lynch (1967), respecto al establecimiento de las Ordenanzas de Intendentes con referencia a la Real Hacienda, esta reforma "no colmó las grandes esperanzas que de él se tenían en el campo de las finanzas" (pp. 133-134). Pero según este autor, algunos factores salían de la responsabilidad de las autoridades del virreinato, como fueron los gastos provocados por la defensa de los territorios coloniales (frente el avance portugués) y la paralización del comercio de exportación que supuso la guerra con Gran Bretaña entre 1796 y 1802, para continuar con las inva-

${ }^{7}$ Moutoukias y Amaral (2010, p. 115) aluden a que las más obvias de las causas de la crisis fiscal de fines de siglo en el virreinato del Río de la Plata eran "los efectos de los rendimientos decrecientes en la producción de plata en Potosí, sobre los ingresos de sus cajas", supongo que quieren decir las cajas altoperuanas o de Charcas, porque Potosí sólo tenía una. Sin embargo, Tandeter (1992) alude a una recuperación en la producción potosina de la década de 1780 hasta principios del siglo XIX. Por otra parte, Chayanta (norte de Potosí) también tenía su máxima producción en la década de los ochenta (Gavira, 2013) Quizá habría que matizar entonces la crisis minera y plantear la crisis fiscal como consecuencia en gran medida del desvío y administración fraudulenta de los recursos de la Real Hacienda.

${ }^{8}$ De la Vega a Soler, Buenos Aires, 25 de mayo de 1803, Buenos Aires, 370, exp. 25. AGI. El visitador Diego de la Vega decía en uno de sus informes sobre las transferencias de los excedentes de las cajas: "en las Cajas Reales y Administraciones de tabaco del Reyno permanecían largo tiempo sus caudales sobrantes sin remitirlos a la tesorería general para sus atenciones y dirección a España, de que provenían las quiebras de los sujetos que los manejaban, valiéndose de ellos para reprobados negocios particulares". 
siones inglesas al virreinato (1806-1807) que terminaron por agotar a la Real Hacienda.

Esto nos induce a pensar que si bien los gastos fueron excesivos y poco controlables, también los ingresos supusieron un problema por lo irregular en cuanto al envío de los situados a la Caja General de Buenos Aires; problemas que tuvo que abordar el visitador general del virreinato y que reflejaban la irregularidad en el manejo de los capitales de la Real Hacienda de las diferentes cajas provinciales. Sin embargo, estas irregularidades no pueden reducirse a la coyuntura especial de principios del siglo XIX (en 1802 se produce la visita), pues como bien demuestra el visitador en sus informes, el caos en el control y la revisión de las cuentas de la Real Hacienda era cuestión de décadas anteriores, es decir, el Tribunal de Cuentas no había realizado su labor de supervisión en años (véase cuadro 1). Habría entonces que preguntarse el porqué de esa deficiencia: falta de funcionarios, falta de interés, estrategia de las elites para defender sus intereses particulares. Es necesario un estudio detallado sobre este Tribunal que nos ayude a entender por qué no funcionaba este órgano de control y por qué era generalizada la impunidad de los funcionarios que administraban los recursos de la administración de la Real Hacienda. Mariluz (1951, pp. 129-156), al valorar la acción de este tribunal, propone algunas causas para su "crítico" resultado: el retraso con que se debatió desde su fundación en la fiscalización de las cuentas, la carencia de empleados indispensables y "la incuria de los obligados a dar cuenta, especialmente los alejados de Buenos Aires". Concluye al decir que cumplió eficazmente su misión en aconsejar a los poderes públicos "y que sirvió en varios casos de valladar a la evasión de los dineros del fisco y de guardián de la honradez de los funcionarios" (p. 156).

Lira $(1998$, p. 31) propone que una de las principales razones para la implantación del régimen de intendencias en Nueva España fue el saneamiento de la Hacienda pública a fin de asegurar los ingresos y su regular administración, si consideramos ese mismo objetivo como fundamental, entonces podremos afirmar que la reforma en el virreinato del Río de la Plata no podría considerarse exitosa, a juzgar por la investigación y declaración del visitador Diego de la Vega en 1802.

\section{LA Visita GENeral AL VIRREINATO DEL Río de LA Plata EN 1802}

Las visitas eran uno de los mecanismos de control administrativo más utilizados por la corona española en los territorios americanos, pero las visitas generales tenían unas competencias y particularidades especiales, pues actuaban en un espacio amplio como eran los virreinatos o las capitanías 


\section{CUADRO 1. REVISIÓN DE LAS CAJAS REALES DEL VIRREINATO DEL RÍO DE LA PLATA POR EL TRIBUNAL DE CUENTAS \\ DE BUENOS AIRES, 1802}

\begin{tabular}{lrrrr}
\hline Cajas Reales & Sin presentar & \multicolumn{1}{l}{ Sin glosar } & \\
Buenos Aires & 1802 & 1 & $1792-1802$ & 11 \\
Montevideo & $1800-1802$ & 3 & $1800-1802$ & 3 \\
Maldonado & 1801,1802 & 2 & $1792-1802$ & 9 \\
Río negro & 1801,1802 & 2 & $1800-1802$ & 3 \\
Santa Fe & 1801,1802 & 2 & $1716-1758$ & 51 \\
& & & $1758-1762$ & \\
& & & 1801,1802 & \\
Paraguay & $1716-1772$ & 60 & $1716-1772$ & 67 \\
& $1799-1802$ & & $1792-1802$ & \\
Córdoba & 1802 & 1 & $1800-1802$ & 3 \\
Mendoza & 1801,1802 & 2 & $1796-1802$ & 7 \\
Salta & 1802 & 1 & $1792,1801,1802$ & 3 \\
Potosí & 1801,1802 & 2 & $1798-1802$ & 5 \\
La Plata & 1801,1802 & 2 & $1798-1802$ & 5 \\
Oruro & $1792-1802$ & 12 & $1785-1787 ; 1789-1802$ & 17 \\
Carangas & 1801,1802 & 2 & $1780-1784 ; 1790-1792 ; 1798-1802$ & 13 \\
Cochabamba & 1801,1802 & 2 & $1782,1785,1786 ; 1799-1802$ & 7 \\
La Paz & $1792,1795-1802$ & 9 & $1781-1802$ & 22 \\
& & & & \\
\hline
\end{tabular}

Fuente: Estado que manifiestan el que tenían las cuentas del cargo de este Tribunal..., 6 de julio de 1802, Buenos Aires, 371. AGI.

generales y con unas atribuciones muy amplias. En el siglo XVIII, algunas de estas visitas generales fueron muy importantes y marcaron un antes y un después, como en el caso de la visita de Gálvez a Nueva España. Otros visitadores, como Areche y Escobedo para el virreinato del Perú, han sido objeto de estudio y contamos con una amplia bibliografía, sin embargo la visita general al virreinato del Río de la Plata realizada por el contador Diego de la Vega no ha levantado tanto interés a pesar de estar repleta de fuertes conflictos y polémica. La razón posible pudiera consistir en que fue una visita tardía y frustrada (Mariluz, 1995; Orellana, 2007).

Las visitas de Gálvez, Areche y Escobedo tuvieron como objetivo renovar, cambiar, establecer una nueva administración; sin embargo la visita de Diego de la Vega tenía como misión supervisar, valorar y evaluar esos cambios que ya habían sido impuestos y que manifestaban su falta de 
eficacia respecto a las reformas en la administración y, en especial, la fiscalidad. Diego de la Vega tenía como objeto principal eliminar "los vicios y abusos" que hacían que el nuevo sistema no funcionara.

El 6 de julio de 1802, Diego de la Vega comenzó una visita general al virreinato del Río de la Plata que consistía, según la real cédula del 22 de febrero de 1802, en "el examen de los verdaderos derechos de SM., de los vicios y abusos introducidos, origen y motivos de éstos y de los medios de removerlos y restablecerla, decidiendo innumerables consultas y expedientes, formando instrucciones y reglamentos para todos los ramos, oficinas y negociados y dando las disposiciones necesarias a la reforma general en la vasta extensión del virreinato". ${ }^{9}$

En diciembre de 1803 el visitador comunicaba el nombramiento del nuevo equipo que había elegido para ayudarle en esta titánica tarea. De la Vega enviaba un informe donde argumentaba su decisión sobre los nombramientos y los sueldos y los comparaba con la visita al virreinato del Perú de José Antonio Areche. Tal como él mismo decía, los sueldos de los integrantes de su equipo eran muy moderados comparados con la anterior visita de 1776, la cual, como hemos comentado, tuvo otras características por estar inmersa en una coyuntura diferente. A principios del siglo XIX las arcas reales estaban muy mermadas y no podían permitirse grandes gastos, pero como De la Vega decía: "la economía no consiste en dexar de gastar, sino en ahorrar lo innecesario o superfluo"10 (véanse cuadros 2 y 3 ).

El fiscal de la Audiencia de Charcas, Victorián Villaba, fue el primero que levantó la alarma por las irregularidades en el manejo de la Real Hacienda en las distintas administraciones comprendidas dentro de la jurisdicción territorial de la Audiencia de Charcas. El fiscal escribía al Consejo de Indias para informar de los incorrectos comportamientos de los oficiales de las Cajas Reales de La Paz, Oruro y Carangas, e informaba de los rumores extendidos desde años atrás sobre las riquezas y lujos que detentaban. Denunciaba a una serie de oficiales suspensos y a otros que abusaban de los caudales públicos sin que se tomaran medidas al respecto. Decía que en el virreinato del Río de la Plata se permitían estos comportamientos y abusos porque no se aplicaba la justicia de forma rápida y eficaz. Pero fue el virrey Joaquín del Pino quien después de tomar posesión terminaría comunicando a la metrópoli los desarreglos de la Real Hacienda del virreinato. ${ }^{11}$

\footnotetext{
${ }^{9}$ Real Cédula, Buenos Aires, 22 de febrero de 1802, Buenos Aires, 370. AGI.

${ }^{10}$ De la Vega a Soler, Buenos Aires, 28 de diciembre de 1803, Buenos Aires, 370, núm. 54. AGI.

${ }^{11}$ Consulta del Consejo, 1801, Charcas, 710. AGI.
} 


\section{CUADRO 2. VISITA AL VIRREINATO DEL PERÚ DE JOSÉ ANTONIO ARECHE Y JORGE ESCOBEDO}

Empleos

Secretario

Contadores

Contadores

Oficial $1^{\circ}$

Oficial $2^{\circ}$

Oficial $3^{\circ}$

Oficial $4^{\circ}$

Supernumerario

Archivero

Escribano

Total
Personas

José Ramos Figueroa

Fernando Saavedra

Pedro Dionisio Gálvez

José del Cavo Franco

Miguel de Arcona

José de Cendeja

José Saenz y Torres

José Muelle y Medina

Juan Suárez

José Senerino
Sueldo anual/pesos

4200

4000

4000

2000

1500

800

600

400

800

2500

20800

Fuente: Razón de los sueldos que gozan los subalternos auxiliares de la visita de Lima y la de Buenos Aires, 28 de diciembre de 1803, Buenos Aires, 370. AGI.

\section{CUADRO 3. VISITA AL VIRREINATO DEL RÍO DE LA PLATA DE DIEGO DE LA VEGA}

\section{Empleo}

Asesor

Secretario

Contador

Oficial $1^{\circ}$

Oficial $2^{\circ}$

Oficial $3^{\circ}$

Oficial $4^{\circ}$

Escribano

Total

\section{Personas}

Juan José Castelli

José Linares Bustillo

Damián de Castro

Fernando Calderón

Ángel de Guerra

Juan Manuel de Luca

Marcelino González

Tirso Martínez

\section{Sueldo anual}

2500

3000

1800

1000

800

600

500

1200

11400

Nota: Razón de los sueldos que gozan los subalternos auxiliares de la visita de Lima y la de Buenos Aires, 28 de diciembre de 1803, Buenos Aires, 370. AGI. 
La real cédula del nombramiento del visitador señala unas competencias muy amplias que comprendían todo el virreinato. Sin embargo, al poco tiempo, De la Vega se quejaba amargamente de las limitaciones impuestas porque la oposición e influencia de algunas autoridades como el virrey consiguieron disminuir las atribuciones de la visita, de manera que quedó restringida al Tribunal de Cuentas de Buenos Aires, el cual era responsable de todo el descontrol existente en las Cajas Reales del virreinato por el retraso en la revisión de los libros contables de dichas instituciones. En agosto de 1804, el visitador De la Vega daba cuenta de haber entregado al virrey todos los papeles y expedientes de la visita general de la Real Hacienda a excepción de los relativos al Tribunal de Cuentas, atendiendo a la real orden fechada el 23 de marzo de 1804. Entonces, como visitador del virreinato tan sólo duró dos años, ${ }^{12}$ aunque continuó con su labor como visitador y contador mayor del Tribunal, dejando una importante evidencia en la reglamentación de esta institución. ${ }^{13}$ Según la opinión del virrey marqués de Sobremonte, su gestión había sido nefasta

[...] así lo noto y observo con sumo dolor, sin dejar tampoco de advertir que todo cuanto hasta ahora ha hecho de la Vega y lo que pretende hacer, ha sido y será poco útil porque en los dos años y meses que han transcurrido desde que abrió su visita no ha sido otra su ocupación que inundar las oficinas con oficios y disposiciones que sólo han servido para innovar y desarreglar en lugar de reformar y organizar, es bien claro que lo mismo sucederá en adelante, cuyos perniciosos efectos ya se están tocando en las competencias que ha preparado y prepara para el Tribunal de cuentas. ${ }^{14}$

Los Tribunales de Cuentas de Lima, México y Santa Fe fueron creados en 1605 poniendo al mando a tres contadores y dos oficiales ordenadores; el personal, igual que el número de Cajas que eran revisadas por estas instituciones, aumentó con el tiempo. En el caso de las Cajas comprendidas dentro de la jurisdicción de la Audiencia de Charcas no se fiscalizaron por el Tribunal de Cuentas de Lima hasta dos años después de la creación del virreinato del Río de la Plata, a donde se traspasó la jurisdicción de este territorio. La revisión de las Cajas Reales altoperuanas pasó en 1778 a ser supervisada por la Contaduría Mayor de Buenos Aires,$^{15}$ que por fin en 1780 se convirtió en el Tribunal Mayor de Cuentas. A pesar de esta con-

${ }^{12}$ De la Vega a Soler, Buenos Aires, 31 de agosto de 1804, Buenos Aires, 372, núm. 150. AGI.

${ }^{13}$ De la Vega a Soler, Buenos Aires, 9 de noviembre de 1805. Buenos Aires, 371. AGI. También fue autor de la primera guía de forasteros del virreinato del Río de la Plata fechada en 1803.

${ }^{14}$ El virrey marqués de Sobremonte a Cayetano Soler, Buenos Aires, 29 de agosto de 1804, Buenos Aires, 372, núm. 82. AGI.

${ }^{15}$ Esta Contaduría fue creada en 1768 . 
solidación, nunca fue considerada una institución muy eficaz tanto por la fama de sus funcionarios como por los atrasos en la revisión de cuentas (Mariluz, 1995). ${ }^{16}$

La Real Ordenanza de Intendentes concentró una gran atención en los intereses financieros y especialmente en los de la Real Hacienda. Se produjeron cambios importantes y se introdujeron nuevas autoridades fiscalizadoras, aunque veremos que la aplicación y los resultados fueron muy relativos o negativos. Por ejemplo, el superintendente de pronto fue eliminado (en 1787) por las tensiones y conflictos que creaba con la figura del virrey, que se vio ampliamente disminuida en asuntos económicos. También se instituyó una Junta Superior de Real Hacienda para auxiliar al superintendente, constituida por los miembros principales del Tribunal de Cuentas, el fiscal de la Real Hacienda, el contador general de la Real Hacienda y el asesor del superintendente (Lynch, 1967, pp. 120-142).

La Ordenanza de Intendentes delegó la jurisdicción económica de cada intendencia en el intendente de cada provincia, auxiliado también por una comisión o junta provincial compuesta por autoridades fiscales (funcionarios de Real Hacienda, administradores de rentas), la cual debía reunirse todas las semanas. Los subdelegados eran los jueces de primera instancia en materia de Real Hacienda en los distintos partidos y se apelaba ante el intendente, excluyendo otros tribunales como las Audiencias. Cada intendencia tenía una Caja Real principal emplazada en la capital de provincia que controlaba todo lo relativo a la recaudación de los impuestos, recibía los excedentes de las Cajas subsidiarias y debía ser supervisada por el Tribunal de Cuentas. Las Cajas que existían antes de 1783 dentro del virreinato fueron: Buenos Aires, Santa Fe, Asunción de Paraguay, Carangas, Potosí, Oruro, Cochabamba, Carabaya, Mendoza, La Plata, La Paz y Chucuito; después se crearon algunas otras para mejor supervisión de las nuevas provincias (véase el cuadro 1). Todos los excedentes de estas Cajas debían de remitirse a la Caja principal del virreinato: Buenos Aires.

Sin embargo, a fines del siglo XVIII, a pesar de toda esta reglamentación sobre la burocracia fiscal y los procedimientos de control, el Tribunal de Cuentas tenía un rezago escandaloso en la revisión de las cuentas de las Cajas Reales. La evaluación del retraso en la supervisión es la que mostramos en el cuadro 1, según el primer reporte del visitador Diego de la Vega en 1802. Es decir, se señalaron algunas Cajas que no habían presentado cuentas desde 1716, como Paraguay; las Cajas de Oruro y La Paz tenían retrasos desde la década de los noventa, lo cual explica en parte que a

\footnotetext{
${ }^{16}$ Se decía de los miembros del Tribunal que el contador Pedro José Ballesteros admitía dádivas a los vecinos y que Juan José de Arroyo estaba en negocios ilícitos y que Ramón de Oromí parecía más agente de negocios que contador de cuentas.
} 
principios del siglo XIX se manifestaran las quiebras de algunas de estas dependencias. Pero además, las cuentas rezagadas de la renta de tabacos eran 335 y del ramo de naipes $112 .{ }^{17}$ Dos años más tarde, en 1804, De la Vega señala que después de una inspección más detallada, las cuentas por finiquitar eran 1003 en toda la jurisdicción del virreinato. ${ }^{18}$

Por lo tanto, no se trata de una coyuntura especial de principios de siglo cuando fue nombrado el visitador, la situación responde a décadas de descontrol y en definitiva a una falta de eficacia de la institución fiscalizadora de las contabilidades provinciales o regionales, los intendentes y el Tribunal de Cuentas. Este caos en la contabilidad del virreinato ya era conocido antes de la visita de 1802. En 1799, el virrey Avilés trató de conseguir un estado general de las finanzas del virreinato y le fue imposible porque

el tribunal de cuentas me manifestó que no podía formularlo por carecer de los precisos datos, de tal suerte que desde el año 1780 en que fue erigido no podía calcular por ningún quinquenio, ni por un año, hasta la actualidad y se contentó con demostrarme que las tesorerías y administraciones interpoladamente habían faltado al envío de sus respectivos estados particulares y generales (Linch, 1967, pp. 128-132).

Otra de las batallas del visitador fueron las matrículas de indios, las cuales también manifestaron grandes retrasos y por tanto innumerables pérdidas para la corona. Según el visitador, la Contaduría de Retasas tenía sin examinar a su llegada 34 revisitas de indios y 38 estaban pendientes de ser aprobadas.

Poco más de dos años duró la visita general, pues el 23 de marzo de 1804 , y ante las presiones del virrey de Buenos Aires, se expedía una real orden reduciendo la visita al Tribunal de Cuentas, de manera que al virrey no le faltó tiempo para hacerse cargo y tomar decisiones de "todos los asuntos que hayan quedado fuera de los límites de su comisión". ${ }^{19}$ El virrey de Sobremonte, no contento con la reducción de competencias, continuó pidiendo la cesión total de De la Vega, pero se le previno que no debía entorpecer la labor del visitador del Tribunal.

\footnotetext{
${ }^{17}$ De la Vega a Soler, Buenos Aires, 25 de mayo de 1803, Buenos Aires, 370, núm. 25. AGI.

${ }^{18}$ De la Vega a Soler, Buenos Aires, 27 de febrero de 1804, Buenos Aires, 371, núm. 82. AGI.

${ }^{19} \mathrm{El}$ virrey marqués de Sobrenombre a Soler, Buenos Aires, 29 de julio de 1804, Buenos Aires, 373, núm. 45. AGI.
} 


\section{Las “Quiebras” de las Cajas de Oruro, Carangas y la Paz}

Las Cajas Reales del Alto Perú eran las encargadas de financiar el nuevo virreinato del Río de la Plata y para ello contaban con dos rubros importantes: plata e indios. Los impuestos sobre la producción de plata y el ramo de tributos eran de los recursos más sustanciosos con que contaba la Real Hacienda. Entre estas Cajas, Potosí era la principal suministradora de recursos y a través del situado se traspasaba el dinero excedente hasta Buenos Aires, como el resto de los excedentes de otras Cajas. Respecto a las Cajas Reales de Oruro y Carangas tenemos que comunicar que son dos distritos mineros que ya hemos trabajado y de los cuales hemos publicado diferentes estudios (Gavira, 2011), por lo que en esta ocasión haremos un breve resumen de la visita encargada por Diego de la Vega al contador del Tribunal de Lima, González de Prada, al cual le tenía mucha confianza pues es posible que se conocieran por compartir trabajo en esta misma institución.

Si se preguntan qué pasaba con la Caja Real de Potosí, que sin duda era la más importante del virreinato, decía De la Vega en un informe que había sido aplazada su inspección para más adelante. Informaba el visitador a Soler que sabía por la información del asesor de la intendencia de Potosí, el doctor Pedro Vicente Cañete, que había graves irregularidades en esta plaza, entre estas se destacaba el abuso de los fondos del Banco de Rescate (suponemos que para esta fecha se trataba del Banco de San Carlos) ${ }^{20}$ el mal manejo de los subdelegados de la provincia con el ramo de tributos y las malversaciones en la Casa de la Moneda, "en que es excesivo el robo, el gasto y el desperdicio". ${ }^{21}$ Entre las razones que argumentaba De la Vega señalaba la poca eficacia que tendría su inspección mientras Potosí tuviese a dos autoridades tan enfrentadas entre sí como eran Francisco de Paula Sanz, gobernador intendente, y su asesor, Pedro Vicente Cañete. El primero gozaba de un carácter "tierno compasivo y liberal", mientras que el asesor estaba resentido con las altas autoridades por no haberle recompensado con una plaza de oidor. De la Vega proponía a Soler que enviase fuera a Cañete para poder entrar a supervisar los intereses de la Real Hacienda en Potosí, ${ }^{22}$ sin embargo no tuvo la oportunidad.

${ }^{20} \mathrm{El}$ gremio de azogueros de Potosí fundó en 1747 la Compañía de Azogueros con la intención de protegerse de los abusos de los habilitadores y comerciantes para poder financiarse y abastecerse de los insumos necesarios a precios más convenientes. En 1751 se convirtió en el Banco de Rescate y posteriormente, a partir de 1779, pasó a ser el Banco de San Carlos (Buechler, 1980, p. 71). Según esta autora, también la gestión y administración de los oficiales reales de Potosí se distinguían por un sistema cada vez más corrupto.

${ }^{21}$ De la Vega a Soler, Buenos Aires, 30 de abril de 1804, Buenos Aires, 371, núm. 118. AGI.

${ }^{22}$ De la Vega a Soler, Buenos Aires, 30 de abril de 1804, Buenos Aires, 371, núm. 118. AGI. De la Vega propone "podría inclinar a S.M. a que le diese plaza en esta Audiencia o en la de la Plata 
La primera en ser visitada fue la Caja Real de Oruro, distrito minero de gran importancia y por tanto una dependencia con gran movimiento. Como asiento minero, los oficiales reales tenían la labor principal de fiscalizar la producción de plata, es decir, recoger los impuestos de 10\% sobre la plata producida, además de otras pequeñas tasas por ensaye y por el abastecimiento de azogue a los propietarios de minas e ingenios, llamados azogueros en esta región andina. Precisamente el suministro de azogues fue objeto de muchas irregularidades entre los oficiales reales que lucraron con la venta de azogues y favorecieron a sus allegados y familiares. También las irregularidades que se destaparon en la Caja de Carangas tenían características semejantes, como veremos a continuación.

Los oficiales reales en el siglo XVIII eran el tesorero y el contador, pero en las cajas de los centros mineros se sumaba el ensayador porque necesitaban tener una persona experta en fundir y ensayar la plata. Es decir, el minero o azoguero llevaba su plata a "quintar", pagar el impuesto en las cajas ante el ensayador, que era el encargado de pesar la plata, fundirla en barras, evaluar y marcar con la ley del mineral. Además de estos cargos principales había otros funcionarios menores, como el oficial mayor. Todos ellos eran cargos vendibles.

La crisis y penuria de la corona fue en aumento durante el siglo XVII, y para buscar soluciones se fomentó la venta y beneficio de cargos de la administración colonial, es decir, los puestos políticos, fiscales, gubernativos e incluso judiciales. Durante el reinado de Felipe IV empezaron a venderse los cargos de Real Hacienda a pesar de la crítica y oposición del Consejo de Indias. Estos funcionarios de Hacienda eran por tanto cargos vendibles, ${ }^{23}$ y cuando se compraban se obtenían en propiedad y podían heredarse. Generalmente era la Cámara del Consejo de Indias la institución que realizaba todos los trámites y presentaba las opciones al rey. En consecuencia, generalmente los oficiales reales se van a distinguir por comportamientos cuestionables motivados por la manera de rentabilizar la inversión e insertarse dentro de las elites locales. Garavaglia (2012, pp. 10-11) ha señalado algunos casos específicos como el del contador de la Caja de Córdoba, Gaspar Lozano, quien consiguió que el cargo lo heredara su hijo. Destaca este autor que a través de las alianzas matrimoniales, en-

de donde es honorario y así quedarían premiados y divididos ambos contenedores el intendente y su asesor y yo más expedito para remediar aquellos males".

${ }^{23}$ No hay que confundir con cargos beneficiados, Sanz Tapia (2009, p. 31) explica muy bien la diferencia entre los dos conceptos, los cargos beneficiados eran aquellos con jurisdicción y no contemplaban la propiedad, se ofrecía un dinero a la corona a cambio del cargo pero no podía heredarse ni transmitirse. La venta de cargos suponía una transacción a título patrimonial y generalmente estaba contemplado para los oficios menores (municipales y fiscales). Los oficios vendidos eran a perpetuidad y con derecho a transmisión, aunque la corona debía aprobar la confirmación. 
tre otras estrategias, las elites locales y la burocracia se aliaban de manera que limitaban "un auténtico proceso de burocratización racional". Sobre los casos de los oficiales de Oruro y Carangas hemos realizado estudios que advierten la implicación en los negocios de minería y la vinculación con las elites locales (Gavira, 2011).

Los cargos en propiedad tenían un sueldo adjudicado que se reducía a la mitad en caso de ejercer el puesto de forma interina, es decir, cuando estos eran nominados por el virrey, presidente o Audiencias, en el caso de estar vacantes y mientras eran proveídos por la corona. Durante el periodo que nos ocupa (segunda mitad del siglo XVIII), el salario que disfrutaban los oficiales propietarios de la Caja de Oruro era de 1957 pesos anuales, y el del oficial mayor consistía en 815 pesos. ${ }^{24}$ Los oficiales de Carangas cobraban 1 620 pesos anuales y el oficial mayor 550 pesos. ${ }^{25}$ En ninguno de estos casos los salarios mostraron ninguna variación durante el medio siglo que hemos revisado detenidamente (Gavira, 2005 y 2008). El oficio de ensayador también era uno de los cargos vendibles, el valor del remate en 1760 alcanzaba los 6000 pesos. En 1774 quedó vacante en la Caja de Oruro por muerte de su último propietario y más tarde, a principios del siglo XIX, "la Intendencia creyó oportuno que dejase de ser vendible". ${ }^{26}$ Para ejercer este oficio, se requería pasar por un examen de conocimientos y práctica de la materia. ${ }^{27}$

Tener acceso a la administración de la Caja Real resultaba bastante ventajoso. Además del control de la distribución del azogue y la disponibilidad de capital para invertir en negocios privados, suponía un importante refuerzo para las alianzas comerciales y, a partir de 1784 , en el caso de Oruro, el control de las propiedades embargadas a los mineros implicados en la sublevación (Gavira, 2005). Pese a la existencia de leyes que prohibían a los oficiales y sus familiares directos o criados beneficiar minas o ingenios ${ }^{28}$ fueron muchos los oficiales que tenían intereses mineros, como podremos observar entre los oficiales de Oruro, La Paz y Carangas. Esta ley sólo tuvo relevancia en el momento en que por rencillas partidarias o por conflictos de competencias era utilizada para la denuncia entre aspirantes o enemistados. En Oruro, con bastante frecuencia, los cargos fueron ejercidos por interinos que residían en la misma villa donde tenían intereses particulares o formaban parte de la clientela de la elite orureña. Por lo

${ }^{24}$ Libros contables de la Caja Real de Oruro, Charcas, 648- 652 (años 1749-1813). AGI.

${ }^{25}$ Caja Real de Carangas, Charcas, 637 y 638 (años 1764-1800). AGI.

${ }^{26}$ Expediente sobre dos postulantes al cargo, Madrid, 1805, Charcas, 711. AGI.

${ }^{27}$ Sobre el examen realizado a José Matías Uriarte para conceder el título de ensayador, Aranjuez, 10 de marzo de 1762, Charcas, 641. AGI.

${ }_{28}$ Que los oficiales reales no beneficien minas ni ingenios (El rey Felipe II en Toledo a 4 de agosto de 1596). Recopilación de las Leyes de Indias (libro VIII, título 4, ley 46). Edición facsímil coeditada por el Centro de Estudios Políticos y Constitucionales y el Boletín Oficial del Estado. Madrid, 1998. 
general, en las fianzas obligadas a propietarios y a interinos aparecían importantes mineros y comerciantes de Oruro y Carangas (para una relación de los oficiales reales de las dos Cajas y su tipo de nombramiento véase Gavira, 2011, pp. 180-182).

\section{La visita de la Caja de Oruro en 1803}

En principio, las instrucciones que se le dieron al visitador comisionado González de Prada consistían en ser lo suficientemente discreto para tomar por sorpresa a los oficiales de Oruro y no dar lugar a recomposiciones. Era conocido que los oficiales podían reponer los desfalcos y las existencias de la Caja cuando se esperaban las visitas.

[...] en la noche del día 4 de agosto durmieron muy descansados de que los efectos de mi visita no les alcanzaría en mucho tiempo viéndome tan distante y ocupado en esta capital pero a las ocho de la mañana del día 5 , al abrir la oficina se vieron sorprendidos por mi comisionado de suerte que no pudieron hacer fuga, ocultar caudales, ni quemar los libros y cuenta de su manejo que frustrase descubrir su infidencia y causase mas gravamen a S.M. ${ }^{29}$

Después de un primer tanteo de los libros contables para calcular el alcance líquido contra los oficiales, se procedió de inmediato a la suspensión, arresto y embargo de los bienes de José Manuel de Santander, Antonio Suárez de Rivera y del subdelegado Ramón Moscoso, que sustituía al tesorero interino. En el informe detallado del cargo contra los oficiales aparecen partidas del ramo de azogues que supuestamente sacaron para sus minas y no abonaron, falta de plata labrada, oro, diamantes y perlas que estaban depositadas en la Caja como fianzas, azogues prestados sin seguridad y otras irregularidades.

El visitador evaluó la quiebra en 236255 pesos que se redujeron a 147827 por el producto del embargo de los bienes. ${ }^{30}$ Se realizó un inventario de todas las minas, ingenios y haciendas que "se deduce han comprado con dinero de S.M. los ministros fallidos, a nombre de sus padres, mujeres y otros individuos" ${ }^{31}$ Estas propiedades se pusieron bajo un interventor para ir pagando la deuda con sus productos, pero el visitador opinaba que lo más acertado, tras la investigación exhaustiva, sería la venta al contado o a plazos. ${ }^{32}$

\footnotetext{
${ }^{29}$ Diego de la Vega a Soler, Buenos Aires, 1803. Buenos Aires, 370. AGI.

${ }^{30}$ Informe de González de Prada, Oruro, 1803, Buenos Aires, 371. AGI.

${ }^{31}$ Diego de la Vega a Soler, Buenos Aires, 1803, Buenos Aires, 370. AGI.

${ }^{32}$ Diego de la Vega a Soler, Buenos Aires, 1803, Buenos Aires, 370. AGI.
} 
Después de que el visitador González de Prada ajustara las cuentas, empezaron los intentos por defenderse. Antonio Suárez de Rivera alegó no haber estado presente en los inventarios y dijo que no era responsable porque había entregado la Caja al subdelegado Moscoso debido a su enfermedad. Las propiedades que le fueron embargadas eran herencia de su padre que las dejó a su mujer, la cual también había sido arrestada junto a su cuñado. Respecto a la justificación de los créditos otorgados sin autorización y sin fianzas, se disculpó de la siguiente manera: "siendo notorio que en dicho todos estos minerales han tocado al último exterminio y los mineros recomendados por V.M. están en la mayor indigencia, a que se agrega que aquella villa no tiene banco, ni fondo de habilitación, y de resultas de la rebelión general se halla sin los ricos vecinos que la hacían floreciente con los auxilios que daban al ramo de minería". ${ }^{33}$

Revisados los libros manuales de estos años, se puede observar que en esta especie de "banco de auxilios", abierto por los oficiales, los requisitos para acceder a los créditos y favores eran los de poseer algún cargo local o estar entre sus allegados. ${ }^{34}$ Respecto al azogue, las deudas mayores fueron contraídas por ellos mismos: Ramón Moscoso (subdelegado de Oruro) tenía una deuda de 17335 pesos, el subdelegado de Paria 5190 pesos, el padre de Antonio Suárez 4 448, Manuela Mier "cuya interesada es la interpósita persona del contador José Manuel Bustillos" 7333 pesos. ${ }^{35} \mathrm{El}$ tesorero no perdía ninguna oportunidad para hacer negocios, incluso los envases donde se transportaba el cobre y el estaño eran proveídos por él.

En 1804, del total de la plata registrada 26\% procedía de las minas e ingenios embargados a los responsables de la quiebra, por lo que podemos suponer que las propiedades de los oficiales eran bastantes rentables. Además de embargarse las propiedades del tesorero, del contador y del subdelegado de Oruro, también se intervinieron las de Teresa Mier y del subdelegado de Paria, Juan Ignacio Mendizabal, quien poseía minas e ingenios. Todos estos propietarios financiaban sus empresas a costa de la Real Hacienda, no sólo en cuanto capital, sino en cuanto al suministro de azogue. Resulta bastante evidente que las propiedades y negocios particulares de la burocracia colonial se financiaban en gran medida con el dinero de la Real Hacienda. Según el visitador general de Buenos Aires, esto era posible, en primer lugar, por la política en los nombramientos, "porque de aquí se recomiendan y apoyan las solicitudes de los empleados por sólo unas informaciones y documentos que fraguó la amistad o el soborno, sin

${ }^{33}$ Carta de Antonio Suárez, 1804, Charcas, 710. AGI.

${ }^{34}$ En el libro Manual de 1803 aparece un apunte en la data indicando la entrega de 1000 pesos a Simón Romano, "regidor del cabildo de Oruro, minero y azoguero, por vía de auxilio para el trabajo de sus labores de minas", 1803, Charcas, 653. AGI.

${ }^{35}$ Diego de la Vega a Cayetano Soler, Buenos Aires, 1804, Charcas, 710. AGI. 
que antes se haga con la reserva y cuidado conveniente para que no quede sorprendido el ánimo de S. M.”. ${ }^{36}$

Otro de los motivos se fundaba en la poca eficacia de los Tribunales de Cuentas,${ }^{37}$ en este caso, el de Buenos Aires nunca llevaba la revisión de las cuentas al día, advirtiéndose la irresponsabilidad de otras instancias superiores, "y es extraño que sus inmediatos jefes y los intendentes de la provincia lo tolerasen". ${ }^{38}$ La solución que propuso el visitador era la supervisión por su parte de todos los nombramientos en relación con la Real Hacienda ${ }^{39}$ y la remisión cada dos meses de las rentas de tabaco y caudales sobrantes de las Cajas principales y foráneas a la Caja General de Buenos Aires. De esta manera, el capital no se acumularía y no daría lugar a la disponibilidad para inversiones particulares. De todas formas, el comisionado volvió a nombrar como oficiales interinos y como subdelegado a vecinos de Oruro con intereses locales y redes familiares ya establecidas.

\section{La visita de la Caja de Carangas 1804}

El visitador González de Prada estaba en Oruro cuando se le comunicó su próxima comisión y decidió partir hasta Carangas sin dar noticias de su nueva visita, donde llegó el día 24 de febrero 1804. A su llegada, "habiendo encontrado la novedad de hallarse cerradas las Cajas y ausente a dos leguas el único ministro que las dirige", ${ }^{40}$ avisó al subdelegado para que lo hiciese comparecer. Después de realizar los inventarios e inspeccionar los libros contables resultó una quiebra de 84988 pesos, que reconoció como legítima el oficial Juan Muñoz Villegas. ${ }^{41}$ Según consta en su confesión, en 1792 realizó un "desfalco" y para reponer ese dinero adquirió una mina

${ }^{36}$ Diego de la Vega a Soler, Buenos Aires, 1803, Buenos Aires, 370. AGI.

${ }^{37}$ Diego de la Vega informa a Cayetano Soler que desde que empezó la visita del Tribunal, del 6 de julio de 1802 hasta el 31 de diciembre de 1803, se han finiquitado 278 cuentas de las que sólo remite 59 porque la mayoría son cuentas precipitadas realizadas por el Tribunal cuando se enteró de la visita, y que se ve obligado a enviar sin las certificaciones de haberse cobrado los alcances líquidos. De la Vega a Soler, Buenos Aires, 1804, Buenos Aires, 371. AGI.

${ }^{38}$ En este caso concreto, Diego de la Vega se refiere a la quiebra de las Cajas de Oruro y La Paz en 1803. Buenos Aires, 370. AGI.

${ }^{39}$ Respecto a los nombramientos parece que Diego de la Vega había acordado con el virrey que él supervisaría los relativos a la Real Hacienda. Más tarde se queja a Soler de los desacuerdos entre ambos, debido a la causa abierta por fraude contra el comandante interino de resguardo D. León Altoaguirre, el cual tenía negocios con el hijo del virrey. Carta a Soler, Buenos Aires, 1803, Buenos Aires, 370. AGI.

${ }^{40}$ Diego de la Vega a Cayetano Soler, Buenos Aires, 1804, Buenos Aires, 371, núm. 110. AGI.

${ }^{41}$ Diego de la Vega a Cayetano Soler, Buenos Aires, 1804, Buenos Aires, 371, núm. 110. AGI. Según los testimonios de González de Prada, "hizo reconocimiento de las piezas que sirven la una de tesorería y la otra de contaduría, las cuales se hallan en un estado de ruina e inseguridad absoluta". 
que acrecentó aún más la deuda. El aludido desfalco, como explica en otra ocasión, tenía que ver con el azogue y argumentaba que se vio obligado a trabajar las minas para reponer un "quebranto anterior que le había producido un considerable derrame y pérdida que experimentó en la especie de azogue", según cita Saguier, (1992, p. 158). De esta manera suponemos que el oficial pretendía justificar la falta de azogue. Sin embargo, y a pesar de tan escandalosos procedimientos, el visitador Diego de la Vega encontraba algunos atenuantes: "la soledad, miseria, la ingratitud de aquel destino, compuesto sólo de unos cuantos ranchos de indios, y el no tener un compañero que interviniese y sujetase su manejo, fueron los motivos que se propendieron a la criminalidad". ${ }^{42}$

Muñoz Villegas ${ }^{43}$ recibió el nombramiento de contador de la Caja Real de Carangas el 26 de noviembre de 1781 y tomó posesión en enero de $1784,{ }^{44}$ por lo que la Caja se quedó en manos del corregidor Chavarri durante los tres años inmediatos a la sublevación indígena, ya que el contador Guemes fue asesinado por los indios y al tesorero Castilla se le concedió la jubilación en 1781. Curiosamente, desde 1780 hasta 1783 no tenemos libros contables pues argumentaron que se habían perdido durante la sublevación indígena. Junto a Muñoz Villegas se nombró como tesorero a Manuel José Uclés, que llegó en 1784 y en 1786 abandonó Carangas para ejercer la secretaría de la Intendencia de Potosí, ya que fue reclamado por Francisco de Paula Sanz como su hombre de confianza; entre otros servicios, estuvo comisionado en Chayanta para investigar los abusos de los eclesiásticos en 1797 (Buechler, 1989, p. 274). En 1787, en un informe sobre los oficiales reales del virreinato, se preguntaban quién estaría realizando la labor de tesorero en Carangas. Curiosamente, aunque Uclés estaba en Potosí, todavía aparecía en los libros contables el nombre de este oficial como tesorero e incluso cobraba su sueldo de oficial propietario. ${ }^{45}$ Por tanto, a partir de esa fecha el oficial Muñoz Villegas gestionó como único oficial los intereses de la Real Hacienda.

La hoja de servicios del contador Muñoz Villegas era bastante completa. Había sido alcalde mayor de Nochistlan (Nueva España) durante 1772, director general de naipes y papel sellado en Lima en 1781, administrador general de la renta de tabaco en el arzobispado de Lima en 1782 y oficial

\footnotetext{
${ }^{42}$ Diego de la Vega a Cayetano Soler, Buenos Aires, 1804, Buenos Aires, 371, núm. 110. AGI.

${ }^{43}$ Cuando se cerró la Caja Real en 1804, el contador tenía 65 años y, según fuentes aportadas por Saguier (1992, p. 158), era natural de Carrión, en Nueva España.

${ }^{44}$ Hoja de Servicio de Juan Muñoz Villegas, 1804, Buenos Aires, 371, núm. 89. AGI.

${ }^{45}$ En la ordenación de las cuentas de la Caja del año 1789 hasta 1793 aparece como tesorero Manuel José Uclés, posteriormente tan sólo aparece el contador Muñoz Villegas. Desde 1784 en adelante el tesorero cobra su sueldo de tesorero propietario que consistía en 1620 pesos anuales. Libros contables de la Caja Real, años 1764-1800, Charcas, 637 y 638. AGI.
} 
de la Caja de Carangas a partir de 1784. Además había sido comisionado por Areche para realizar visitas en las provincias de Cajamarca y Lambayeque. Pero lo que no deja de llamar la atención es que, a pesar de haber sido sorprendido en el desfalco de la Real Hacienda, el visitador informaba a la corona que intentaba buscar nuevos puestos para los oficiales de Carangas, los cuales quedarían sin destino al cerrarse esta Caja. La hoja de servicio de Muñoz Villegas, fechada en 1804, resumía sus cualidades de esta manera: aptitud: bastante; talento: superior; conducta: irreprochable; aplicación: constante. Habrá que preguntarse hasta dónde tenían que llegar las conductas corruptas de la burocracia para ser descalificados en el ejercicio de sus competencias. ${ }^{46}$

El visitador general del virreinato, Diego de la Vega, era mucho más contundente con la parte de responsabilidad que les correspondía a las altas instituciones. Consideraba que el Tribunal de Buenos Aires y la superintendencia deberían haber descubierto la deuda mucho antes, pues se advertía el desfalco por pura lógica. No era normal que si en las cuentas se establecía la existencia de dinero, no se mandara con el situadista como eran las órdenes. Otra vez se argumentaba la responsabilidad del Tribunal por el retraso en la supervisión de las cuentas, pero sin duda también se inculpó de forma indirecta a los intendentes.

La quiebra descubierta en la caja de Carangas, a principios del siglo XIX, terminó por cerrar esta institución, quedando el partido de Carangas bajo la jurisdicción económica de la Caja de Oruro. La decadencia minera de este partido no justificaba el mantenimiento de esta institución, cuyos ingresos provenían, en gran parte, de las minas de Tarapacá. Las autoridades del virreinato de Buenos Aires no atendieron a ninguna otra consideración, pues Tacna (Arica) ya tenía callana donde fundir la plata de Huantajaya. ${ }^{47}$ Los informes que llegaban sobre el mineral de Carangas eran totalmente desalentadores, en concreto se calificaba a este centro minero de "cadáver".

${ }^{46}$ Diego de la Vega a Cayetano Soler, Buenos Aires, 1804, Buenos Aires, 371, núm. 89. AGI. La hoja de servicios de Muñoz Villegas va incluida con una carta donde informa del cierre de la Caja de Carangas, del nuevo destino del oficial mayor Carrafa en la Caja de Cochabamba y la intención de buscar nuevos destinos para Muñoz y Uclés.

${ }^{47}$ En 1731 un bando del virrey Castelfuerte obligaba a los mineros de Huantajaya (costa chilena) a registrar su plata en la Caja Real de Carangas, por ser la caja más cercana que tenía callana y ensayador (Gavira, 2008, p. 51). 


\section{La visita de la Caja de La Paz,1803-1812}

Los problemas e irregularidades provocados por los oficiales reales implicados, junto con los derivados de los que se generaron en las esferas más altas, como gobernador intendente y visitador, provocaron que la visita de La Paz fuera un proceso complejo y largo, se tardó mucho más tiempo en llegar a una resolución que en el caso de Oruro y Carangas. Podríamos decir que la visita duró desde la llegada de Diego de la Vega en 1802 hasta 1812, año en que la terminó el mismo visitador de forma personal y, por supuesto, una vez ya concluida la visita general. Las personas implicadas también llegaron a ser más numerosas.

La Caja de La Paz tenía una serie de visitas por irregularidades durante las últimas décadas del siglo XVIII, entre las cuales nombraremos como antecedente la llevada a cabo en la década de los sesenta, descubriéndose un alcance a los oficiales reales que fueron depuestos por la falta de 27497 pesos. ${ }^{48}$ Durante la década posterior fueron nombrados oficiales propietarios el tesorero coronel Miguel Antonio del Llano y el contador Pedro Nolasco Crespo. El primer conato de irregularidades en la gestión de estos oficiales ocurrió durante 1782, cuando ejercían dos sustitutos ${ }^{49}$ mientras los oficiales propietarios estaban en la cárcel de Potosí, dando cuentas de su gestión, aunque al parecer salieron absueltos.

La visita más importante que tuvieron los propietarios implicados en la quiebra de la Caja, el contador Pedro Nolasco (criollo) y el tesorero Fulgencio Suárez (peninsular), fue en 1795, cuando el oidor supernumerario y asesor del intendente de Potosí, Pedro Vicente Cañete (personaje de gran influencia en el Alto Perú) revisó los libros contables sin que se dedujeran graves irregularidades para el contador, y tan sólo se depuso temporalmente al tesorero Suárez. Sin embargo, el conflicto más grande se generó entre Cañete y el intendente de La Paz, Burgunyo. Como visitador de la aduana, Cañete intentó resucitar varios impuestos como el de alcabalas, que según el intendente perjudicaba en gran medida al comercio local, sin embargo la oposición de los hacendados paceños y del intendente ganaron la partida al visitador y quedó suspendida esa comisión (Lynch, 1967, p. 131). En 1804, De la Vega pedía instrucciones a Soler para saber si podría retomar este problema y reponer el impuesto de alcabalas a los hacendados de las Yungas (La Paz) productores de coca; no sabemos la respuesta pero parece que no se produjo novedad al respecto. ${ }^{50}$

\footnotetext{
${ }^{48}$ Los oficiales eran Ignacio José de Bracader y Aguilar y a Francisco Ángel Bravo de Rueda. Expediente de embargo, La Paz, 1770. Caja 15, doc. 2. Archivo Histórico de La Paz.

${ }^{49} \mathrm{El}$ contador Juan Esteban Muñoz y Manuel de Sagarnaga. Caja 16, año 1782. Archivo Histórico de La Paz.

${ }^{50}$ De la Vega a Soler, Buenos Aries, 30 de abril de 1804, Buenos Aires, 371. AGI.
} 
Años después, Diego de la Vega comisionó para la inspección de esta Caja al contador Antonio Zubiaga, quien encontró un descubierto de 118 420 pesos, procediendo a suspender a los dos oficiales responsables y a embargar sus propiedades. Sin embargo, este trámite fue largo y con muchas dificultades. Pero además de este alcance, había una relación de deudas estimadas en 1000000 de pesos. Decía el visitador De la Vega:

por el catálogo de deudores que casi todos los vecinos de La Paz estaban afectos al pago y que de proceder contra todos por la estrepitosa vía executiva de embargos, prisiones, depósitos, tasaciones y subastas era arruinar y destruir aquel vecindario con daño permanente y sucesivo de sus comercios y giros en que tanto lucro dejan al Rey [...] he prevenido secretamente a mi comisionado a fin de precaver males de tanto bulto y las fatales consecuencias que podrían sobrevenir que aunque en el exterior demuestre que va a proceder a tales apremios executivos, los entable con prudencia, arbitre con maña el cobro y dilate con pretextos los embargos. ${ }^{51}$

Las deudas de los vecinos de La Paz se encontraban recogidas en el libro denominado de "Lastos", ${ }^{52}$ donde aparecían las deudas de particulares respecto a la Real Hacienda y que estaban al cuidado de los oficiales, aunque según el contador Nolasco, estas estaban valuadas en poco más de 25000 pesos y no en 1000000 de pesos, como argumentaba el visitador. ${ }^{53}$

Los oficiales responsables fueron depuestos y sus bienes embargados. El contador Nolasco poseía haciendas en el partido de Chulumani, distintas casas en La Paz y cinco tiendas, y el tesorero, que se encontraba en paradero desconocido en la península, poseía parte de un lavadero de oro en la provincia de Larecaja. ${ }^{54}$ Decía el visitador en este mismo informe que se asombraba de que no hubiesen sido descubiertos por el intendente anterior, Fernando de la Sota, cuya obligación era revisar y hacer tanteos de las cuentas, y por el asesor de Potosí, Pedro Vicente Cañete. Al mismo tiempo también se depuso al administrador de la renta de tabacos de La Paz, Tomás Orrantía, por la falta de más de 25000 pesos. ${ }^{55}$

La supervisión del comisionado Antonio de Zubiaga (criollo nacido en Buenos Aires) estimó la deuda por irregularidades en 119000 pesos. El contador Nolasco se defendía y eludía su responsabilidad diciendo que

${ }^{51}$ De la Vega a Soler, Buenos Aires, 29 de octubre de 1803, Buenos Aires, 370, núm. 48. AGI.

${ }^{52}$ Según el diccionario de la Real Academia Española, lastar significa: "suplir lo que alguien debe pagar, con el derecho a reintegrarse".

${ }_{53}$ Expediente del Sr. Visitador Don Antonio de Zubiaga a la Caja de la Paz, fechado a principios de octubre de 1803. Caja. 18. Archivo Histórico de La Paz.

${ }_{54}^{5}$ Diego de la Vega a Soler, 28 de diciembre de 1803, Buenos Aires, 370, núm. 56. AGI.

${ }^{55}$ Decía De la Vega que este sujeto estaba acostumbrado a la malversación y el desorden y que ni siquiera había dado fianzas cuando se incorporó en 1787. Diego de la Vega a Soler, 29 de octubre de 1803, Buenos Aires, 370, núm. 49. AGI. 
salió en 1796 de la Caja por enfermedad. Respecto a la deuda de 1794 dice que no puede ser posible que resultase esa cantidad, precisamente mientras Cañete realizaba la visita a la Caja. El contador Nolasco murió en La Paz en 1805 y todavía no habían alcanzado a recuperar la deuda con las propiedades y posesiones embargadas. Diego de la Vega sospechaba de la existencia de ocultaciones en su inventario y señalaba que debían buscar alhajas, esclavos y muebles, los cuales no habían sido reportados. ${ }^{56}$

Sin embargo, en 1805 volvía a complicarse el proceso de inspección de la Caja de La Paz, pues el intendente Burgunyo denunciaba al visitador comisionado Zubiaga por cohecho y malversación de los caudales de la Real Hacienda. Decía el intendente que el visitador estaba implicado en contrabando. El conflicto entre las dos autoridades debió ser muy fuerte para terminar en semejantes denuncias ante el virrey. Desde Aranjuez se envió una resolución diciendo que la revisión de las cuentas de La Paz fuera efectuada por Diego de la Vega y que lo hiciera como visitador y no como contador del Tribunal de Cuentas. Este detalle nos hace vislumbrar los conflictos de competencias, especialmente los creados por su colega Oromí, contador del Tribunal de Cuentas y por el mismo virrey, pues en esta fecha la visita había quedado reducida al Tribunal de Cuentas.

El visitador respondía que sus ocupaciones no le permitían salir de Buenos Aires y que ya se había asignado a González de Prada para que cuando terminase Oruro y Carangas pasase a La Paz a revisar esta Caja. $\mathrm{Al}$ parecer, De la Vega no quería trasladarse a La Paz. Nos preguntamos si le temía al viaje, a la altura o a los conflictos en La Paz. Argumentaba también sobre los inconvenientes de contar con la actitud de Burgunyo, y le sorprendía que hubiera manifestado una gran falta de interés respecto a los manejos de los oficiales reales y sus fraudes, y en cambio tuviese mucho celo en la supervisión que le hizo al comisionado Zubiaga ${ }^{57} \mathrm{Al}$ final, en 1806, fue nombrado González de Prada como visitador de La Paz.

Una vez muerto el intendente Burgunyo, en 1808, De la Vega había recomendado a González de Prada para el cargo de intendente de La Paz. El virrey nombró a este gobernador pero tan sólo en lo relativo a la Real Hacienda, y a Tadeo Dávila en lo relativo a lo político y justicia, sin prever, decía De la Vega, las tensiones que surgieron entre ambos. Parece que se dieron muchos conflictos y el virrey decidió nombrar un nuevo intendente gobernador y cesar definitivamente en la visita a González de Prada, quien se jubiló en 1809 y se retiró a vivir a Cochabamba.

\footnotetext{
${ }^{56}$ Carta Diego de la Vega al intendente de La Paz, 18 de marzo de 1806, caja 132. Archivo Histórico de La Paz.

${ }^{57}$ Visitador De la Vega a Soler, Buenos Aires, 26 de octubre de 1805, Buenos Aires, 372, núm. 164. AGI.
} 
Para resumir, diremos que sobre la visita a La Paz no se puede precisar cuánto dinero se recuperó de la famosa deuda contraída por los vecinos. Los acontecimientos de estos años hicieron difícil imponer la regularidad hacendista y política. En 1809 se enviaron las resultas de la deuda que, según De la Vega, consistía en 119380 pesos, además de los 118000 que encontró Zubiaga y de los cuales tan sólo se habían recuperado 24000 pesos; pero ese mismo año la Caja Real fue asaltada y por tanto se acabó con la posibilidad de terminar de cobrar las deudas pendientes.

Fechada en enero de 1810, encontramos una carta de Diego de la Vega diciendo que se le había nombrado gobernador intendente de La Paz pero que no se sentía seguro de viajar y gobernar en una provincia donde se habían producido "anarquía y lastimosos sucesos", decía que allí era necesario un gobierno militar porque "la experiencia de todos los tiempos nos enseña que las semillas de una revolución no se extingue de un solo golpe y que aun después de disipados sus autores debe obrar la misma fuerza" ${ }^{58}$ Los acontecimientos en Charcas y La Paz durante 1809 fueron de inestabilidad y conflictos entre distintas autoridades e instituciones con diferentes posturas ante la detención de la familia real, la instauración de las diferentes juntas en la península y la pretensión de la reina Carlota Joaquina. El tumulto en la ciudad de La Paz provocó que se asaltaran las instalaciones de la Caja Real y se quemara la lista de deudores a la Real Hacienda. La represión de este movimiento en La Paz estuvo a cargo de Goyeneche y acabó con los líderes ejecutados en enero de 1810. Por lo tanto, la negativa de Diego de la Vega a asumir el gobierno de la intendencia de La Paz estaba argumentada por una situación de conflicto político que le haría muy difícil el gobierno y restablecimiento de la normalidad en la administración hacendística de esta intendencia, que tenía además una Caja Real saqueada (Roca, 1998 y Soux, 2010).

De la Vega tuvo una gestión llena de polémica pero muy activa y decisiva en cuanto a la reglamentación y reordenación de la administración de la Real Hacienda, más allá de la visita del Tribunal de Cuentas. Entre sus legados se encuentra la reglamentación del mismo Tribunal, una primera guía de forasteros de la ciudad de Buenos Aires, el intento de acabar con el sistema contable de las Cajas Reales imponiendo el método de partida doble en 1806, instrucciones para los ramos de cruzadas y de indulto cuadragesimal y otras muchas normativas. En 1804 consiguió permiso para casarse con Ana de Riglos, natural de Buenos Aires, hija de Javier Riglos.

\footnotetext{
${ }^{58}$ Diego de la Vega, Buenos Aires, 2 de enero de 1810, Buenos Aires, 372. AGI.
} 
De este matrimonio nació un hijo que enviaron a los once años a la península para que "no se criara con los insurgentes". ${ }^{59}$

\section{Conclusiones}

Se supone que los excedentes de las Cajas Reales altoperuanas debían financiar el reciente virreinato del Río de la Plata y dos rubros fundamentales fueron la minería y el tributo indígena. El Alto Perú, o la región comprendida dentro de la Audiencia de Charcas, era propicia en plata y población indígena, ambas cuestiones eran la base de la economía colonial. Sin embargo, encontramos muchas evidencias que cuestionan el control que sobre estos sectores tenía la administración colonial. Debemos señalar la importancia del contrabando de plata, las matrículas de indios manipuladas, los impuestos al comercio sin aplicar (impuesto a la coca de Yungas), toda una serie de irregularidades fiscales que manifiestan un control paralelo por parte de las elites locales, en las cuales se encontraba inserta la burocracia colonial. Tan sólo parece que cumplió con esta misión de enviar los excedentes la Caja Real de Potosí, aunque queda por precisar cuánto dinero se desvió por otros conductos y nunca llegó a Buenos Aires.

Las quiebras de las distintas Cajas que hemos analizado demuestran que efectivamente había excedentes producto de los distintos impuestos que llegaron a aplicarse, y esto nos induce a pensar que el problema radicaba entonces en la administración; es decir, los funcionarios no hacían llegar el dinero a la Caja General de Buenos Aires. Este capital fue utilizado por los oficiales para invertir en sus negocios particulares (generalmente mineros) y los de sus allegados, como es el caso de los préstamos que hacían a los familiares y amigos los oficiales de Oruro. En otras ocasiones no se aplicaron o recaudaron ciertos impuestos como se demuestra en el caso de La Paz, donde el impuesto correspondiente a la producción de coca era muy reducido o se mantenían las deudas de los vecinos sin recaudar (libro de Lastos). En definitiva, si anteriormente en el Buenos Aires de fines del siglo XVII había un pacto donde todos ganaban, según Moutoukias (1988), para fines del siglo XVIII continuaban las mismas prácticas en la economía colonial. La corona intentaba tomar el control y aumentar su parte del pastel a partir de la aplicación de las Ordenanzas de Intendentes y otras medidas impositivas; sin embargo, como podemos observar a partir de la información de la visita de 1802, esto no le garantizó el éxito. Es decir, los recursos y la producción que generaban las elites pagaban sus impuestos

${ }^{59}$ Carta de María del Carmen de Cárdenas, Madrid, 26 de noviembre de 1829, Buenos Aires, 372. AGI. 
pero estos excedentes no siempre terminaban vía Buenos Aires hacia la península.

Las quiebras de las Cajas tenían algo en común, podrían haberse evitado si los mecanismos de supervisión se hubieran aplicado. No sólo la burocracia fiscal era la responsable, sino que otras autoridades y otras instituciones no cumplieron con sus competencias. ¿¿ónde estaba entonces la eficacia de la renovación administrativa?, ¿dónde estaba entonces "la revolución en el gobierno"? La burocracia borbónica continuaba con las mismas prácticas de "servicio a cambio de beneficios" aceptadas por la sociedad, y se trataba, como bien dice Salvucci (1983), de "hombres nuevos y viejas costumbres", o quizá ni siquiera hombres nuevos. ${ }^{60}$ Las elites continuaban ejerciendo su influencia entre autoridades y burocracia "corruptas" o familiares; y en la alianza de ambos grupos se gestaron estrategias para obviar la rigidez y la centralización que pretendía imponer la reforma en la administración. Las consecuencias que acarreó este caos y crisis fiscal, y las condiciones de inestabilidad política de principios del siglo XIX, plantearon, como argumentan Moutoukias y Amaral (2010), una nueva cultura política fiscal como transición a una nueva realidad que no tardaría en imponerse.

\section{LISTA DE REFERENCIAS}

Andujar Castillo, F. y Felices de la fuente, M. Del M. (2011). El poder del dinero. Venta de cargos y honores en el Antiguo Régimen. Madrid: Biblioteca Nueva.

BERTRAND, M. (1989). En torno a una problemática de la administración colonial: La Real Hacienda de Nueva España (1680-1770). Anuario de Estudios Americanos, 46, 195-217.

Bertrand, M. (1999). Grandeur et Misère de l'ofice. Les officiers de finances de NouvelleEspagne, XVII-XIII sicles. París: Grand Public.

Brading, D. (1975). Mineros y comerciantes en el México borbónico (1763-1810). Madrid:

Fondo de Cultura Económica.

Buechler, R. M. (1980). La Compañía de Azogueros y el Banco de Rescates de Potosí (17471779). Buenos Aires: Imprenta de la Universidad de Buenos Aires.

Buechler, R. M. (1989). Gobierno, minería y sociedad: Potosí y el renacimiento borbónico, 1776-1810. La Paz: Biblioteca Minera Boliviana.

${ }^{60}$ En los partidos de Oruro y Carangas (Gavira, 2005 y 2008) los subdelegados nombrados eran parte de la elite local de Oruro puesto que no había quien ejerciera un cargo sin sueldo (3\% del tributo) y sin posibilidad de ganancias por repartimientos de mercancías. Respecto a los oficiales reales y sus nombramientos véase Gavira, 2011. 
Canga Agüelles, J. (1827). Diccionario de Hacienda, vol. 4. España: Imprenta de M. Calero.

CÉspedes, G. (1983). América hispánica (1492-1898). Barcelona: Labor.

Fisher, J. (2000). El Perú borbónico, 1750-1824. Lima: Institutos de Estudios Peruanos.

Garavaglia, J. C. (2012). Servir al Estado, servir al poder: la burocracia en el proceso de construcción estatal en América Latina. Almanack. Guarulhols, 3, 5-26.

GaVira, M. C. (2005). Historia de una crisis: la minería en Oruro a fines del periodo colonial. La Paz: Instituto Francés de Estudios Andinos/Universidad Mayor de San Andrés/Universidad Michoacana de San Nicolás de Hidalgo.

Gavira, M. C. (2008). Población indígena, sublevación y minería en Carangas. Arica: Universidad de Tarapacá/Instituto Francés de Estudios Andinos.

GavirA, M. C. (2011). El escándalo de las quiebras en la Real Hacienda: las de Oruro y Carangas, 1784-1804. Bolivian Studies Jornal, 8, 161-183.

Gavira, M. C. (2013). Minería en Chayanta. La sublevación indígena y el auge minero 17751792. La Paz: Plural Editores/Universidad Michoacana de San Nicolás de Hidalgo.

Halperin Donghi, T. (1982). Guerra y finanzas en los orígenes del Estado argentino (17911850). Buenos Aires: Ed. Belgrano.

JÁUREgui, L. (enero-marzo, 2003). Vino viejo y odres nuevos: la historia fiscal en México. Historia Mexicana, 52(3), 725-771.

Jiménez, A. (2012). Poder, dinero y ventas de oficios y honores en la España del Antiguo Régimen: un estado de la cuestión. Cuadernos de Historia Moderna, 37, 259-272.

Klein, H. (1985). La economía de la Nueva España, 1680-1809: un análisis a partir de las Cajas Reales. Historia Mexicana, 49, 561-609.

Klein, H. y Dos Santos, M. (julio-septiembre, 1973). Las finanzas del virreinato del Río de la Plata en 1790. Desarrollo Económico, 13(50), 369-400.

LIRA, A. (1998). Aspecto fiscal de Nueva España en la segunda mitad del siglo XVIII. En L. Jauregui y J. A. Serrano (coords.), Las finanzas públicas en los siglos XVIIIXIX (pp. 27-65). México: Instituto de Investigaciones Dr. José María Luis Mora/El Colegio de Michoacán/El Colegio de México/Universidad Nacional Autónoma de México.

LYNCH, J. (1967). Administración colonial española, 1782-1810. El sistema de intendencia en el virreinato del Río de la Plata. Buenos Aires: Editorial Universitaria de Buenos Aires.

LyNCH, J. (1989). Bourbon Spain, 1700-1808. Oxford: Basil Blackwell.

MARILUZ, J. M. (enero-abril, 1951). El tribunal Mayor y Audiencia Real de Cuentas de Buenos Aires. Revista Facultad de Derecho y Ciencias Sociales, 23. Recuperado de www.larramendi.es/ i18n/catalogo_imagenes/grupo.cmd?path=1000289

Mariluz, J. M. (1995). La causa de Hacienda. En Estudios sobre la Real Ordenanza de Intendentes del Río de la Plata (pp. 83-111). Buenos Aires: Instituto de Investigaciones de Historia del Derecho.

Moutoukias, Z. (1988). Burocracia, contrabando y autoformación de las elites. Buenos Aires en el siglo XVII. Anuario IHES, 3, 213-248. 
Moutoukias, Z. y Amaral, S. (2010). Las tramas de la acción política. Crisis fiscal, tolerancia comercial y construcción institucional. Buenos Aires, 1809. Anuario IEHS, $25,97-118$.

Orellana, E. A. (2007). Evolución de la contabilidad desde los Incas hasta la partida doble. Buenos Aires: Ediciones Cooperativas.

PÉrez, P. (1991). Los beneficiarios del reformismo borbónico: Metrópoli versus elites novohispanas. Historia Mexicana, 41(2), 207-264.

Pietschmann, H. (1987). Estado colonial y mentalidad social. El ejercicio del poder frente a distintos sistemas de valores. Siglo XVIII. En A. Franco (comp.), Dallo Estato coloniales allo Estato nazione (V. II, pp. 427-447). Torino: Université de Torino.

Pietschmann, H. (1989). El Estado y su evolución a principios de la colonización española en América. México: Fondo de Cultura Económica.

RocA, J. L. (1998). La revolución de la Audiencia de Charcas en Chuquisaca y en La Paz. La Paz: Plural Editores.

SAGUiER, E. (1992). La corrupción de la burocracia colonial borbónica y los orígenes del federalismo. El caso del Virreinato del río de la Plata. Jarbuch fur Geschichte von Staat Wirtschafts und Gessellschaft Lateinamerikas, 29, 224-264.

SAlvuCCI, L. (1983). Costumbres viejas "hombres nuevos”, José de Gálvez y la burocracia fiscal novohispana, 1745-1800. Historia Mexicana, 33(2), 224-264.

San-Martino, L. (1999). Constitución indiana de Carlos III. La Real Ordenanza de Intendentes de 1782. Buenos Aires: Editorial Ciencias de la Administración.

Santamaria, D., Gelman J., Klein H., Marquiegui D., Millones L. y Garavaglia J. (1990). Estructuras sociales y Mentalidades en América Latina. Siglos XVII y XVIII. Buenos Aires: Fundación Simón Rodríguez/Editorial Biblios.

SAnZ, A. (2009). ¿Corrupción o necesidad? La venta de cargos de Gobierno americano bajo Carlos II (1674-1700). Madrid: Consejo Superior de Investigaciones Científicas.

Soux, M. L. (2010). El complejo proceso hacia la independencia de Charcas (1808-1826). La Paz: Instituto Francés de Estudios Andinos/Plural Editores/Asociación para el Desarrollo Internacional.

TAndeter, E. (1992). Coacción y mercado. La minería de la plata en Potosí colonial 16921826. Buenos Aires: Editorial Sudamericana.

TAndeter, E. (1995). Población y economía en los Andes (siglo XVIII). Revista Andina, 13(1), 7-43.

\section{OTRAS FUENTES}

\section{Archivos}

AGI Archivo General de Indias, Sevilla, España.

AHP Archivo Histórico de La Paz, La Paz, Bolivia. 